\title{
COMPETÊNCIAS ORGANIZACIONAIS DESENVOLVIDAS PELA ESCOLA NACIONAL DE ADMINISTRAÇÃO PÚBLICA COMO ESCOLA DE GOVERNO (1986-2016)
}

Organizational Competences Developed by the National School of Public Administration as School of Government (1986-2016)

\section{Competencias Organizativas Desarrolladas por la Escuela Nacional de Administración Pública como Escuela de Gobierno (1986-2016)}

\section{RESUMO}

Esse artigo versa sobre competência organizacional em administração pública. 0 objetivo é compreender as competências organizacionais desenvolvidas pela Escola Nacional de Administração Pública (ENAP) como escola de governo. Para cumprimento desse objetivo, adota-se uma abordagem teórico-metodológica histórica, utilizando-se, como técnicas de levantamento de informações, pesquisa documental e entrevista com recurso à história oral temática; e, como técnica de análise, a análise temática. Nessa compreensão histórica, evidenciaram-se como competências organizacionais desenvolvidas pela ENAP no cumprimento de seu propósito como escola de governo: ter a marca ENAP; formar competência para a gestão; ser espaço de encontro de competências; e interpretar demandas. A história dessas competências organizacionais foi marcada por processos adaptativos, emergentes e incrementais, 0 que fez a ENAP como escola de governo.

PALAVRAS-CHAVE: história organizacional, escola de governo, administração pública, competência organizacional, recursos humanos no setor público.

\section{Manuela Ramos da Silva ${ }^{1}$}

mrs.gusmao@gmail.com

ORCID: 0000-0001-5739-6593

Monica de Aguiar Mac-Allister Silva²

monica.macallister@ufba.br

ORCID: 0000-0002-4852-1898

1 Universidade Federal de Sergipe(UFS)/Programa de Pós-Graduação em Administração (PROPADM)

2 Universidade Federal da Bahia (UFBA)/ Núcleo de Pós-Graduação em Administração(NPGA)

Submetido 15-12-2019. Aprovado 11-04-2020

Avaliado pelo processo de double blind review

Editor científico: Fernando Coellho

DOI: http://dx.doi.org/10.12660/cgpc.v26n83.80861

Esta obra está submetida a uma licença Creative Commons 


\section{ABSTRACT}

This article discusses organizational competences in public administration. The objective is to comprehend the organizational competences developed by ENAP as a government school. To fulfill this objective, a historical theoretical-methodological approach was applied, using documental research and interview with thematic oral history as information gathering techniques; and documental analysis and thematic analysis as analytical techniques. In this historical comprehension, having the ENAP brand, forming competence for administration, being a space for the meeting of competences and interpreting demands were considered as organizational competences developed by ENAP in the fulfillment of its purpose as a government school. Adaptive, emergent and incremental processes marked the history of these organizational competences which made of ENAP a school of government.

KEYWORDS: organizational history, school of government, public administration, organizational competence, human resources in the public sector.

\section{RESUMEN}

Este artículo trata sobre la competencia organizacional en la administración pública. El objetivo es comprender las competencias organizacionales desarrolladas por la ENAP como escuela de gobierno. Para el cumplimiento de este objetivo se adopta un enfoque teórico-metodológico histórico, utilizando como técnicas de relevamiento de informaciones la investigación documental y entrevistá con recurso de la historia oral temática; y como técnicas de análisis el análisis documental y Análisis Temático. En esta comprensión histórica, se evidenciaron tener la marca ENAP, formar competencia para la gestión, ser espacio de encuentro de competencia, y Interpretar demandas, como competencias organizacionales desarrolladas por la ENAP en el cumplimiento de su propósito como escuela de gobıerno. La historia de estas competencias organizativas fue marcada por procesos adaptativos, emergentes e incrementales que hicieron de la ENAP una escuela de gobierno.

PALABRAS CLAVE: historia organizacional, escuela de gobierno, administración pública, competencia organizacional, recursos humanos en el sector público.

\section{INTRODUÇÃO}

As escolas de governo foram criadas como parte integrante e indispensável do processo de reforma e modernização do Estado, em diferentes países no mundo e inclusive no Brasil, resguardando as particularidades de cada contexto, mas aparentemente com o mesmo propósito de formar recursos humanos para o setor público, no esforço de capacitar e formar administradores de alto nível. Na atuação como escolas de governo e em função do cumprimento do propósito para o qual foram criadas, essas organizações desenvolvem competências.

Competência refere-se a uma capacidade de realizar, seja individual, grupal ou organizacionalmente, por meio da mobilização de recursos frente a um contexto específico (Ruas, Ghedine, Dutra, Becker \& Dias,
2005). Trata-se aqui, especificamente, de competência organizacional, como a capacidade de uma organização, em um contexto, mobilizar recursos e realizar. (Becker, 2004; Dias, 2011; Fleury \& Fleury, 2004; Munck \& Dias, 2013).

O conceito de competência organizacional foi desenvolvido, quase que exclusivamente, para organizações empresariais, sendo as públicas praticamente ignoradas. No entanto, o exame das competências organizacionais e da forma como elas se desenvolvem nas organizações públicas podem trazer uma nova perspectiva de análise.

Bryson, Ackermann \& Eden (2007, p.702) consideram que "uma chave importante para o sucesso de organizações públicas é identificar e construir as capacidades estratégicas para produzir o maior valor público possível 
para os principais stakeholders a um custo razoável" [tradução nossa). Tão importante quanto colocar em ação a competência é a capacidade de compreender o processo de desenvolvimento das competências organizacionais no âmbito da gestão pública. Atenta-se para a importância de desvendar o que está por trás daquilo que uma organização pública efetivamente entrega para a sociedade como chave para seu bom desempenho.

Ao estudar o processo de formação e desenvolvimento de competências organizacionais em uma organização pública, Quintana (2009) contribuiu para a adaptação dos conceitos de competência organizacional para a administração pública e, de forma correlata, desempenho organizacional e vantagem competitiva.

Com base em Bryson et al. (2007) e Quintana (2009), define-se competência organizacional, considerando as especificidades da gestão pública, como capacidade de combinar e integrar recursos em produtos e serviços, de forma contínua, visando a criação de valor público e a efetividade na gestão do setor público, que justifiquem a sua existência como organização pública.

Pressupondo que as escolas de governo são organizações públicas que desenvolvem, em seus contextos e ao longo do tempo, competências que possibilitam suas atuações em função do propósito para as quais foram criadas, questiona-se: quais as competências organizacionais desenvolvidas pela Escola Nacional de Administração Pública (ENAP) como escola de governo? O objetivo deste artigo é compreender as competências organizacionais desenvolvi- das pela ENAP como escola de governo, desde sua criação em 1986, no contexto da reforma administrativa do Governo Sarney (1985-1990), até 2016, respondendo a diversos contextos, ao longo de aproximadamente 30 anos de atuação.

Para cumprimento desse objetivo, adota-se uma abordagem teórico-metodológica que segue os princípios da história nova, como sugerido por Costa \& Costa (2015). Delineia-se um estudo histórico no campo da administração pública como história organizacional, construindo a história da ENAP e, nessa perspectiva histórica, interpretando as competências desenvolvidas por essa organização pública em sua atuação como escola de governo, de 1986 a 2016.

As informações foram levantadas por meio de pesquisa documental e entrevistas. Os documentos foram analisados, considerando as cinco dimensões de avaliação crítica propostas por Cellard (2008). A análise documental permitiu a identificação dos presidentes e diretores da ENAP de 1986 a 2016 como sujeitos passíveis de entrevista. Junto dessa análise documental, aplicou-se a técnica de bola de neve (Gray, 2012). Foram entrevistados os seis ex-presidentes; quatro ex-diretores, dois diretores, dois funcionários, dois professores e um assessor da presidência, no período de outubro de 2015 a fevereiro de 2016. Esses sujeitos vivenciaram a história da ENAP, com diferentes vínculos institucionais e temporais e apresentaram seus pontos de vista a partir das suas próprias experiências. Para a realização das entrevistas semiestruturadas utilizou-se 0 recurso da história oral temática (Meihy \& Ribeiro, 2011) 
Como técnica de análise de informações, utilizou-se a análise temática baseada em Braun e Clark (2006) e Cunliffe (2011). Sob essa técnica processaram-se codificação, seleção de citações da fala dos entrevistados, identificação de temas, notas de análise, elaboração de rede de relações entre os códigos e as citações, bem como nuvem de palavras. Ao analisar as entrevistas, não se procurou estabelecer um consenso, um discurso do sujeito coletivo ou uma narrativa totalizante e sim reconhecer a visão individual de cada entrevistado que de alguma maneira representou as demandas e necessidades, bem como os projetos de cada ciclo de gestão da ENAP. Optou-se, também, por não identificar os entrevistados, não tão somente para preservar o anonimato, mas pela decisão por priorizar o sentido e o significado dos temas que surgiram do corpus como um todo.
Esse artigo está dividido em três seções. $\mathrm{Na}$ primeira seção, que é esta introdução, são apresentados tema-problema, objetivo e escolhas epistemológicas, teóricas e metodológicas. Na segunda seção, as competências organizacionais desenvolvidas pela ENAP como escola de governo são interpretadas, bem como seus elementos constitutivos, com apoio de literatura sobre o tema. Na terceira seção, de conclusão, são sintetizados os principais resultados e as sugestões estudos futuros.

\section{COMPETÊNCIAS ORGANIZACIONAIS DE- SENVOLVIDAS PELA ENAP COMO ESCO- LA DE GOVERNO}

Foram interpretadas quatro competências organizacionais desenvolvidas pela ENAP, definidas e descritas no Quadro 1.

Quadro 1. Competências organizacionais desenvolvidas pela ENAP

\begin{tabular}{|l|l|}
\hline COMPETÊNCIA & DESCRIÇÃO \\
\hline MARCA ENAP & $\begin{array}{l}\text { Capacidade de transformar a força e o reconhecimento da marca em confia- } \\
\text { bilidade e qualidade na entrega, alinhamento aos objetivos e problemas do } \\
\text { governo e seriedade na produção, transformação e difusão do conhecimento } \\
\text { em administração pública, amparada pela sua trajetória organizacional. }\end{array}$ \\
\hline $\begin{array}{l}\text { FORMAÇÃO DE } \\
\text { COMPETÊNCIA } \\
\text { DE GESTÃO }\end{array}$ & $\begin{array}{l}\text { Habilidade e comprometimento com a formação da competência de gestão } \\
\text { (em pessoas e em organizações), por meio do ensino aplicado, considerando } \\
\text { os diversos níveis de atuação e de tomada de decisão dos atores envolvidos } \\
\text { no processo de gestão da política pública. }\end{array}$ \\
\hline $\begin{array}{l}\text { ESPAÇO DE EN- } \\
\text { CONTRO DE COM- } \\
\text { PETÊNCIAS }\end{array}$ & $\begin{array}{l}\text { Capacidade de mobilizar e congregar diversidade de pessoas, conhecimento } \\
\text { e práticas, configurando-se num espaço de encontro de competências em } \\
\text { gestão pública. }\end{array}$ \\
\hline INTERPRETAÇÃO & $\begin{array}{l}\text { Habilidade de compreensão e interpretação do ambiente institucional, no qual } \\
\text { está inserida, visando a aumentar a efetividade do seu papel organizacional e } \\
\text { da entrega, a partir das demandas dos atores e organizações públicas. }\end{array}$ \\
\hline
\end{tabular}




\section{Marca ENAP}

A Marca ENAP é entendida aqui como capacidade de transformar sua força e seu reconhecimento em confiabilidade e qualidade na entrega, alinhamento aos objetivos e problemas do governo e seriedade na produção, transformação e difusão do conhecimento em administração pública, amparada pela sua trajetória organizacional.

O fato é que a escola é uma grife e isso faz uma grande diferença. (trecho de entrevista) Difícil de ser adquirido, imitado e substituído é a grife mesmo, o prestígio da grife ENAP. (trecho de entrevista)

Eu acho que esse deve ser o carro-forte da escola mesmo, a marca da escola. (trecho de entrevista)

Apesar dos relatos de que nos primeiros anos a ENAP teve que empreender ações visando a sua sobrevivência institucional, a marca é uma competência organizacional inquestionável na história da escola. Os marcos temporais identificados pelos entrevistados para a construção do reconhecimento e da confiabilidade da marca são, em 1986, a sua concepção e criação, quando assumiu o papel de formar os quadros superiores permanentes de carreira como a principal estratégia de modernização e reforma do setor público.

Em 1995, houve a sua institucionalização, quando ocorreu uma "virada organizacional": de escola com papel difuso e resultados pontuais, mesmo considerando sua missão "nobre", para escola empoderada, com papel claro e reconhecido, em alinhamento com as políticas de gestão do governo federal, como uma estratégia deliberada.
A marca ENAP está associada aos fatores confiança, respeito e reconhecimento das suas ações e qualidade das entregas, desde sua criação, como se evidencia nos relatos a seguir:

Algo que passe pelo crivo da ENAP, eu acho que é confiável, ou seja, é imagem de seriedade no que faz. ) (trecho de entrevista)

As pessoas têm uma confiança nos produtos da ENAP, elas sentem que a ENAP é uma instituição séria, que é comprometida com aquilo que faz, que tem um compromisso com a administração pública (trecho de entrevista)

A ENAP seleciona muito bem seus professores, ela qualifica seus professores internamente. Então é uma coisa de fácil imitação (trecho de entrevista))

A ENAP tem nome consolidado fora do país. (trecho de entrevista)

Constatou-se que a marca acompanhou a trajetória de altos e baixos da escola, mantendo-se mesmo nos momentos em que o propósito da ENAP não foi valorado pelo governo federal; sendo essa desvalorização evidenciada entre 1987 e 1992, devido ao esvaziamento da entidade, associado à ausência de uma política definida de recursos humanos, à falta de concursos e à extinção da carreira de gestor governamental. As medidas adotadas pelo governo federal acarretaram um efeito desorganizador sobre a administração pública e criou uma situação de incerteza em relação ao papel e à atuação esperada da escola. Naquele período, sofreu com o esvaziamento de suas atividades e a perda de prestígio e relevância. 
Constatou-se, também, que a ENAP desenvolveu ao lado da competência da marca, uma capacidade de adaptação e resiliência no percurso da sua história, uma vez que ela segue no seu papel de escola de governo.

A qualidade das entregas foi citada pelos participantes da pesquisa como presente em várias ações e práticas da escola.

A ENAP tem qualidade do seu corpo de professores. Tem qualidade do curso e do material didático. (trecho de entrevista) Uma certa respeitabilidade da ENAP sobre a qualidade da entrega. Há qualidade dos cursos. (trecho de entrevista)

Quer que o curso seja bom antes de mais nada. Ele (aluno) quer que o curso seja bom: o material didático, o professor, a metodologia. Ele quer que a instalação seja boa, quer que a metodologia seja instigante, ele quer que o curso esteja atualizado, que a estratégia de ensino seja adequada, ele quer que o professor domine o conteúdo, ele quer tudo isso. (trecho de entrevista)

Em outras palavras, esta característica, que está relacionada a várias ações, tais como conteúdo, corpo docente, material didático, foi considerada, para fins deste estudo, como um elemento fundamental na constituição da marca ENAP.

Outro elemento importante para a construção em dessa marca é o esforço de adaptação de conteúdo, material e metodologia para o setor público, seja de conceitos e experiências identificados no contexto internacional, seja de conceitos e práticas oriundos da gestão empresarial.
Tudo que a ENAP oferece é difícil de imitar: ela tem essa particularidade, porque as coisas que nós discutimos aqui, elas são de todos, customizadas para as necessidades do setor público. E nisso nós temos um papel significativo! (trecho de entrevista) (...), uma capacidade de ler a minha práti$\mathrm{ca}$, mas ler o mundo também, no qual eu [me) insiro, para saber fazer as melhores opções e para saber também desenvolver, adaptar e desenvolver minhas tecnologias. [...) Então, existe essa particularidade. Eu diria para você que tudo o que a gente já tem feito, a gente tem feito no esforço, enfim, [de) particularizar essas coisas para as necessidades do setor público (trecho de entrevista)

Então, tudo o que passa por aqui, principalmente em desenvolvimento técnico-gerencial, precisa ter um esforço de adaptação, precisa ter um esforço de leitura e de releitura. (trecho de entrevista)

É reconhecido que a gestão pública tem suas especificidades e o mesmo acontece no Brasil, sendo imprescindível a adequação dos conteúdos e das metodologias utilizados pela ENAP nas suas atividades de formação. Para alguns, a formação e o desenvolvimento da competência da marca ENAP são atribuídos ao "'monopólio da sua atuação" e, em correlato, por "ter vantagem competitiva (da formação) da carreira de gestores públicos; ter uma grande infraestrutura e facilidade da contratação do (seu) serviço (...)" (trecho de entrevista).

Seguindo a mesma linha, outros entrevistados afirmam que a ENAP “(...) nem tem por que ter monopólio de nada (...)"; "não tem uma expertise por si"; e "não acho que a 
ENAP é uma jabuticaba" (trecho de entrevista).

Acredita-se que tais visões subestimam o aprendizado coletivo e os efeitos cumulativos da história organizacional e consideram apenas as questões relacionadas ao direito administrativo.

Apesar dos diversos aspectos narrados pelos sujeitos da pesquisa, a marca ENAP está sustentada pela confiança, pelo respei- to e reconhecimento nas ações e entregas, qualidade das entregas, que por sua vez é apoiada pela flexibilidade e adaptação da entrega à gestão pública. Imitar ou replicar o que a marca ENAP é hoje demandaria um investimento e um esforço institucional enormes.

Os elementos que sustentam esta competência emergiram de maneira consistente e expressiva através das narrativas e podem ser resumidos na Figura 1.

Figura 1. Elementos da marca ENAP

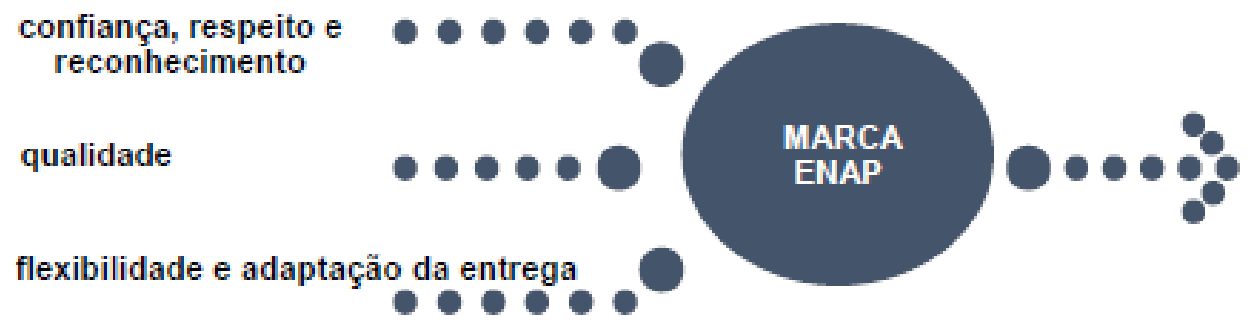

Formação de competência de gestão

Quando solicitados a descreverem o que a ENAP faz bem feito, os participantes da pesquisa destacaram como diferencial o desenvolvimento da competência para a gestão, voltado para os servidores, gestores e dirigentes envolvidos na gestão das políticas públicas e das organizações públicas, preservando a identidade como uma escola nacional e não específica de algum setor.

O business da escola, vamos dizer assim, é gestão pública. E é um diferencial interessante da escola e que ao longo do tempo se manteve. (trecho de entrevista) Então talvez o diferencial da escola que pode ser difícil para qualquer outra é ser tão amplo, acho que todo o governo fe- deral. Então eu acho que a gente tem um espaço privilegiado. (trecho de entrevista) (...) na verdade eu acho que sempre demandou da escola essa visão organizacional de como é que nós podemos aperfeiçoar a gestão das nossas organizações (trecho de entrevista)

As universidades não têm que saber qual é a realidade técnica das prefeituras. Podem até fazer pesquisa sobre isso, mas saber como lidar com isso não é papel da universidade. Esse é o papel da escola de governo. Eu vejo com muita clareza isso. Aqui sim é que as competências organizacionais começam a ficar mais claras. (trecho de entrevista)

(O) diferencial da ENAP é essa proximidade que ela tem com a gestão (trecho de entrevista) 
Essa competência está relacionada à identidade da escola, que tem a gestão como foco para sua atuação em ensino, pesquisa e assistência técnica, por meio dos princípios do ensino aplicado.

A vocação para o ciclo de gestão e a formação voltada para a prática e para os "saberes corporativos do governo" revelaram-se fortes e presentes em toda a trajetória histórica da ENAP. Apenas para relembrar: a razão para a sua criação foi a seleção e formação da carreira de Especialista em Políticas Públicas e Gestão Governamental (EPPGG), seguindo nesse propósito até 1990 , quando passa a atuar também no treinamento dos demais servidores públicos federais do Poder Executivo. Seguindo com o fortalecimento das carreiras agora denominadas de "estratégicas" pela reforma gerencial, passa a atuar na capacitação de dirigentes e gerentes do Plano Plurianual (PPA), chegando ao desenvolvimento de competências dos servidores para ampliar as capacidades de governo.

Atuando como escola nacional de administração pública, sem uma vinculação a algum setor específico, a ENAP sempre teve a gestão como conteúdo articulador da sua atuação. Isso é mostrado pelas ações emergentes, ainda nos seus primeiros anos de história organizacional, assim como por ações deliberadas, a partir de 1995. Mesmo com as diversas mudanças e transformações legais, institucionais e de seu modelo de formação, a ENAP sempre teve na gestão o princípio norteador para o seu desempenho como escola de governo.

Formar competência para a gestão é uma capacidade que está relacionada à criação da ENAP e ao seu objetivo de recrutar, formar e aperfeiçoar os integrantes da carreira de EPPGG, bem como às estratégias de sobrevivência na seleção e formação do Analista de Planejamento e Orçamento (APO) e de Analista de Finanças e Controle (AFC). Tal competência também foi requerida na retomada da carreira de EPPGG, na formação de gerentes e dirigentes da PPA e na gama de servidores em funções estratégicas e de assessoramento, visando, ao longo da sua história organizacional, a desenvolver competências técnicas, políticas e analíticas, por meio dos princípios do ensino aplicado e da aprendizagem significativa.

$\mathrm{Na}$ tentativa de atualizar a discussão se esclarece que as escolas de governo, por suas características, são diretamente relacionadas às estratégias de governo, ou seja, a atuação das escolas de governo deve ter foco na ampliação da capacidade de governar (Amaral, 2004, 2005; Ferrarezi, Zimbrão \& Amorim, 2008; Fernandes, 2015).

A capacidade de formar competências para a gestão é constituída pela articulação de alguns recursos: conectividade com o governo e ensino aplicado.

A competência de formar para gestão também está relacionada à conexão da ENAP com a prática do governo, as organizações públicas e os seus desafios.

(A) ENAP pode prestar uma grande contribuição neste campo, estando dentro da administração pública: uma coisa é o olhar exógeno; outra coisa é o olhar de quem está dentro. (trecho de entrevista)

(O) grande diferencial da ENAP é o de ser 
uma escola de governo dentro do governo, de não ser uma instituição acadêmica e de não ser apenas uma instituição de formação profissional (trecho de entrevista)

O fato de estar dentro da máquina, essa é a fortaleza (da ENAP). (trecho de entrevista)

Quanto ao alinhamento das ações da ENAP aos objetivos e problemas do governo, foi interpretado aqui como elemento que faz parte da concepção da ideia de escola de governo, ou seja, esta escola de governo está intrinsecamente atenta às demandas e aos problemas da ação de governo, sem com isso perder a sua capacidade de reflexão e crítica. Essa era a posição em que a ENAP se encontrava em 2017, sendo este aspecto considerado como um dos elementos da competência de formação de competências para a gestão. Entende-se que a competência organizacional é uma ação que traz um diferencial, no caso da gestão pública, uma vantagem comparativa e não aquilo que ela tem por dever fazer; o que se evidencia nas falas a seguir:

(É) raro ter alguma proposta da ENAP ou coisa assim, totalmente desligada dos interesses do governo. (trecho de entrevista)

A dinâmica de articulação dessa escola na convergência de diferentes competências que discutem, que dialogam e que problematizam a questão do setor público. É uma coisa impressionante. (trecho de entrevista)

Eu acho que o diferencial das coisas que acontecem aqui dentro... são coisas que dialogam com o setor público, (...), se não ela não funciona. É um processo de cons- trução entre um pedido e isso virar uma demanda a ser atendida, há um processamento que na ENAP, em várias áreas dela, se desenvolveu, (...) (trecho de entrevista)

Então, em parte isso se deve à origem e em parte foi uma preocupação ao longo da trajetória. A escola, por exemplo, nunca foi associada a (uma) escola do planejamento (trecho de entrevista)

O ensino aplicado foi idealizado, juntamente com a ideia inicial da ENAP, como "escola prática de governo". Este modelo de ensino foi inspirado também na École Nationale d'Administration (ENA), que se reconhece como "escola de aplicação", cuja pedagogia privilegia a reflexão e a análise a partir de situações concretas e a interação grupal no desenvolvimento de atividades, usando tanto técnicas quanto instrumentos didáticos compatíveis.

Quer dizer, os cursos teórico-aplicados nascem com a escola desde os primeiros documentos. (trecho de entrevista)

É um diferencial, então, que ela tem para oferecer: é o ensino aplicado. (trecho de entrevista)

Ensino aplicado: (é o) que faz sentido (ao) falar de escola de governo, é isso que diferencia, em geral, uma escola de governo de uma instituição de ensino superior stricto sensu (trecho de entrevista)

Ensino aplicado e metodologia ativas: uma escola de governo que não valoriza isso, está perdendo tempo (trecho de entrevista)

Como observado nos depoimentos, este elemento constitutivo da formação de competência para a gestão está diretamen- 
te relacionado ao papel de uma escola de governo, assim como apresenta desafios à sua implementação. Na trajetória da ENAP, o ensino aplicado teve muitas variações na sua prática. Nas turmas de formação dos EPPGG, nos anos de 1996, 1997, 1998 e 1999, foram excluídas "estratégias importantes para esse intento com a retirada da etapa de estágio na estrutura curricular e da disciplina aplicada Prática de Políticas Públicas." O estágio retornou à estrutura curricular do curso em 2002.

Uma melhor compreensão da prática do ensino aplicado seria possível em trabalhos de pesquisa cujo objetivo seja centrado nas atividades pedagógicas da ENAP, na análise dos programas de formação e dos trabalhos finais de curso, o que não é o caso do trabaIho ora em tela.
Em parte, o valor "formação de competência para a gestão" está relacionado ao propósito de criação da ENAP e aos papéis que foram desempenhados ao longo da sua trajetória, pois, apesar da sobreposição das organizações no seio da sua criação, a competência de formação para a gestão permaneceu em prática, definindo assim o comportamento e atuação da escola ao longo do tempo, tanto no âmbito da formação quanto na educação continuada.

A competência de formação de competência para a gestão foi desenvolvida e é renovada com os servidores públicos e as organizações públicas, devido à constituição de um locus de formação e de aperfeiçoamento que a ENAP se tornou ao longo do tempo. Os elementos que sustentam esta competência podem ser resumidos segundo a Figura 2.

Figura 2. Elementos da competência Formação para a Gestão

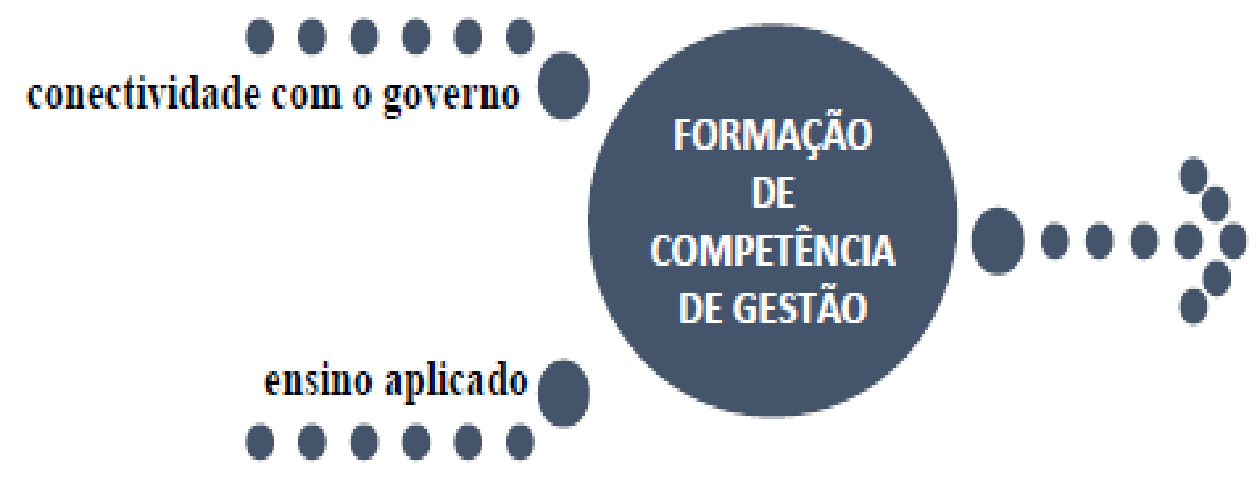

Espaço de encontro de competências

Segundo Holanda (2005), um aspecto importante no projeto de criação da ENAP foi 0 de estabelecer um fórum permanente no qual fosse possível analisar e discutir, em profundidade, de forma crítica e criativa, os grandes problemas nacionais, particularmente as suas relações com o Estado, o go- verno e a função pública do Brasil. "Ou seja, imaginávamos, naquela época, que a ENAP funcionária, também, além de ser um centro de formação, como um centro de pesquisas, de fóruns de debates." (p. 26)

Pela interpretação dos depoimentos coletados, tal competência extrapola o papel de articulação e coordenação da ENAP jun- 
to à Rede Nacional de Escolas de Governo e ao Sistema de Escola de Governo da União, pois o que está sendo considerado é a capacidade de mobilização e congregação de diversas pessoas, conhecimentos e práticas visando ao valor público das ações empreendidas pela escola. Tal competência não é atribuída tão somente à prerrogativa legal que a ENAP tem de coordenação dos demais centros de formação, mas ocorreu pelo seu posicionamento e desempenho no campo das escolas de governo e pela sua marca, construídos historicamente.

Ela atrai competências, então, quando você consegue reunir aqui as maiores competências que estão na máquina pública, mesmo que (...) da academia mas que conhecem bem a área pública, quando isso aqui consegue reunir, você agrega valor. Então, você concentra aqui, vamos dizer, os conhecimentos. Esse é o maior o fator mais significativo do meu ponto de vista. (trecho de entrevista)

Você tem uma diversidade de competências de visão, que em lugar nenhum você consegue trazer (trecho de entrevista)

ENAP é uma instituição em que tem essa diversidade de visões, de interpretações, de propostas de política, é saudável, é necessário para o debate, para reflexão, etc. Então, ela tem um... ela tem esse papel, e só com a existência da escola que é possível ter isso. ENAP é a memória da construção e debate de PP (trecho de entrevista)

Além da capacidade de mobilizar e congregar pessoas, conhecimentos e práticas, a ENAP age como vetor de conexão e difusão de saberes. Diferentemente, dos primeiros anos em que enfrentou críticas e resistência das universidades, hoje há diálogo e parceria, principalmente na produção e difusão do conhecimento.

O aspecto da difusão do conhecimento, relatado anteriormente, está associado ao propósito da ENAP, e foi bastante citado pelos entrevistados, em contraponto a um dos itens considerados frágeis na história da escola: a pesquisa. Os entrevistados lembram que a prática de pesquisa da ENAP deve ser aplicada, voltada para a investigação de problemas práticos do fazer governamental, bem como valer-se de métodos que busquem solucionar as questões do "mundo real." Há uma crítica quanto à pesquisa acadêmica, uma vez que o tempo da solução esperada para os "problemas públicos" é iminente.

A partir da análise documental, identificou-se que a produção e disseminação de informações foi um tema estratégico abordado pela ENAP no período de 2001 a 2003, por conta de seu vínculo com a qualificação permanente dos dirigentes e gerentes estratégicos do governo federal.

No seu papel de difusão de conhecimento, a ENAP mantém a Revista do Serviço Público (RSP), um dos motivos de orgulho da escola, que faz parte das atividades estratégicas para que ela cumpra seus papéis.

Outra coisa, (...), pelo menos, da ENAP de ser e se tornar também um centro editorial, de editoração, de publicações. (trecho de entrevista)

Então publicações foi um ponto importante, a Revista do Serviço Público que foi muito importante a gente traduzir artigos do debate internacional. (trecho de entre- 
vista)

Outro importante componente da missão da ENAP na difusão do conhecimento em gestão pública é a Biblioteca Graciliano Ramos. Assim como a Casoteca, um acervo virtual de estudos de caso com foco na administração pública. Os casos são de acesso gratuito e pretendem estimular o uso de técnicas inovadoras para o ensino, cobrindo temas como ética, políticas públicas, diversidade, gestão de programas e projetos, inovação e outros.

Em paralelo às publicações próprias, a ENAP sempre teve a preocupação de traduzir e publicar livros de referência nos diversos temas relacionados à gestão pública.

No seu papel de difusão de conhecimento e práticas de gestão pública, a ENAP promove o concurso Inovação no Setor Público, anualmente, desde 1996, em parceria com o Ministério da Economia.

A conexão de saberes é fortalecida pela prática da cooperação internacional. A partir dos depoimentos coletados e da análise documental, foi possível compreender que este é um aspecto marcante na história organizacional, desde a sua origem.

Buscar novos conhecimentos e metodologias aplicáveis à realidade da administração pública brasileira, trazer o olhar externo para a atuação da ENAP, repensar e avaliar constantemente a produção da escola. É com esses objetivos que a instituição vem sendo conduzida, ao longo de sua trajetória, pelas ações de cooperação internacional, pela experiência do Programa de Parcerias e pela mobilização da Rede Nacional de Escolas de Governo (ENAP, 2006).

Essa rede é a configuração do espaço de interlocução, troca de informações e identificação de pontos de apoio entre as instituições de formação e capacitação de servidores públicos. Foi idealizada com o objetivo de reduzir o isolamento e ampliar as capacidades das escolas de governo federais, estaduais e municipais, por meio do compartilhamento de conhecimentos e experiências e do incentivo à formação de parcerias. Desde 2003, a ENAP iniciou a articulação desse espaço.

Quando o tema é pesquisa, novamente surge a questão da fragilidade de não possuir um quadro funcional com as competências desejadas e alinhadas aos propósitos e objetivos organizacionais da ENAP.

(...) mas na área de pesquisa a ENAP nunca foi um IPEA (trecho de entrevista)

(...) de pesquisas importantes que tenham influenciado políticas públicas no Brasil, (...), ela nunca conseguiu se estabelecer nessa área. (trecho de entrevista)

(...) porque a ENAP, ela não tinha, nunca teve um orçamento grande, ... era um lugar que poderia ter um corpo mínimo, sempre foi uma discussão que nós tivemos na escola, por que a gente não tem um corpo mínimo? Por que? Isso ia garantir várias coisas. (trecho de entrevista)

Ao mesmo tempo que se entende que a ENAP não avançou nas questões relacionadas à pesquisa, em parte, por conta do corpo funcional, há uma clareza de que a pesquisa deve ser voltada para a prática e não seguir a tradição do modelo acadêmico. De maneira geral, admite-se que os problemas de governo demandam soluções aplicadas. 
COMPETÊNCIAS ORGANIZACIONAIS DESENVOLVIDAS PELA ESCOLA NACIONAL DE ADMINISTRAÇÃo PÚBLICA COMO ESCOLA DE GOVERNO (1986-2016)

Figura 3. Elementos da competência Espaço de Encontro de Competências

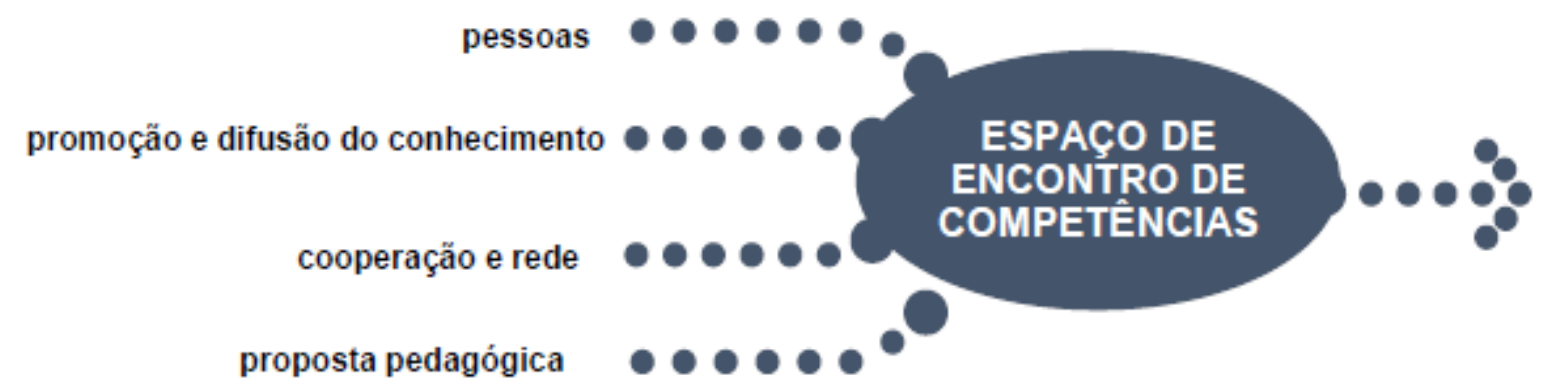

Resume-se na Figura 3 os elementos que constituíram a competência de ser um espaço de encontro de competências, conformando a ENAP como um espaço plural, crítico e autônomo na produção e difusão do conhecimento em gestão pública no Brasil, ao longo da a sua história, convergindo assim em um espaço propício de encontro de competências individuais, coletivas e organizacionais, no pensar e na prática da ação administrativa do governo.

\section{Interpretação de demandas}

Ao passo que se identificou a competência de interpretar as demandas dos seus principais usuários, também se questionou a semelhança entre essa competência e a competência de ser espaço de formação de competências. Mas há uma diferença clara entre elas. A competência de interpretação de demandas do governo, dos servidores e das organizações públicas extrapola a capacidade de convergência e congregação de pessoas, conhecimentos e práticas em gestão pública. Em outras palavras, o fato de se constituir como o espaço de encontro de competências não é condição sine qua non para a interpretação das demandas. Outros elementos são necessários para a constituição dessa capacidade de interpretação do ambiente institucional no qual a escola está inserida, com vistas à efetivida- de do seu papel organizacional e das suas entregas, a partir das demandas dos atores e das organizações públicas.

(...) um esforço enorme com os diretores, é o que nós tínhamos que ter com esse interlocutor com o cliente institucional capaz de interpretar demanda (trecho de entrevista)

Tem uma competência instalada de fazer bem, pelo menos a escuta às demandas que chegam desses órgãos, a decodificação disso, às vezes o dizer não. (trecho de entrevista)

A busca deles pela ENAP é a possibilidade da escola compreendê-los em suas demandas específicas (trecho de entrevista)

Entre 1999 e 2001, inicia-se a oferta de cursos de especialização em gestão pública, também de cursos à distância, além de encontros da rede nacional de escolas de governo e a criação da livraria da ENAP. Assim como a continuidade de ações importantes relacionadas ao desenvolvimento de dirigentes, aos acordos de cooperação internacional, publicação e tradução de obras importantes no campo da gestão pública.

A partir de 2002, a ENAP não foi direcionada por um plano de reforma administrativa, como no período anterior. Contudo foi capaz de captar as necessidades que perma- 
neciam e as novas demandas do governo federal para organizar e planejar as suas ações de formação, pesquisa e assistência técnica. $\mathrm{O}$ impacto da falta de uma diretriz clara quanto à atuação da ENAP é indicado na fala de um dos entrevistados:

(...). sei lá 2010-2011-2012 sei lá, acho que mais ou menos esse período, a ENAP esteve um pouco afastada da realidade, da necessidade, da demanda, da realidade da demanda das instituições. Porque a ENAP tem seus produtos fixos, seus produtos, um levantamento necessário para isso, mas as instituições precisam de muita coisa customizada e a ENAP me parece que não tem ainda ou deixou de ter, durante um tempo, essa agilidade de customização necessária, porque ela precisa ser contratada pela instituição (trecho de entrevista)

Estimular a organização de centros de reflexão e pesquisa que pudessem contribuir para o conhecimento da realidade econômica, política e administrativa do Brasil, favorecendo a criação de uma cultura e de uma tecnologia administrativa adaptadas às nossas necessidades foi descrita por Holanda (2005) como uma característica que a ENAP teve no seu projeto de criação, como escola de governo.

Nesse sentido, entende-se que esteve presente esta capacidade de leitura e compreensão do ambiente organizacional no qual está inserida a ENAP, tanto nos períodos nos quais contou com um plano de atuação, quanto e, principalmente, naqueles em que não havia clareza de uma diretriz e uma expectativa do desempenho da escola. De uma maneira ou de outra, houve desenvolvimento de aspectos cognitivos e acúmulo de aprendizado organizacional na ENAP para interpretar o cenário e as demandas externas.

Os elementos da competência para interpretar as demandas são resumidos na Figura 4.

Figura 4. Elementos da competência Interpretação de Demandas

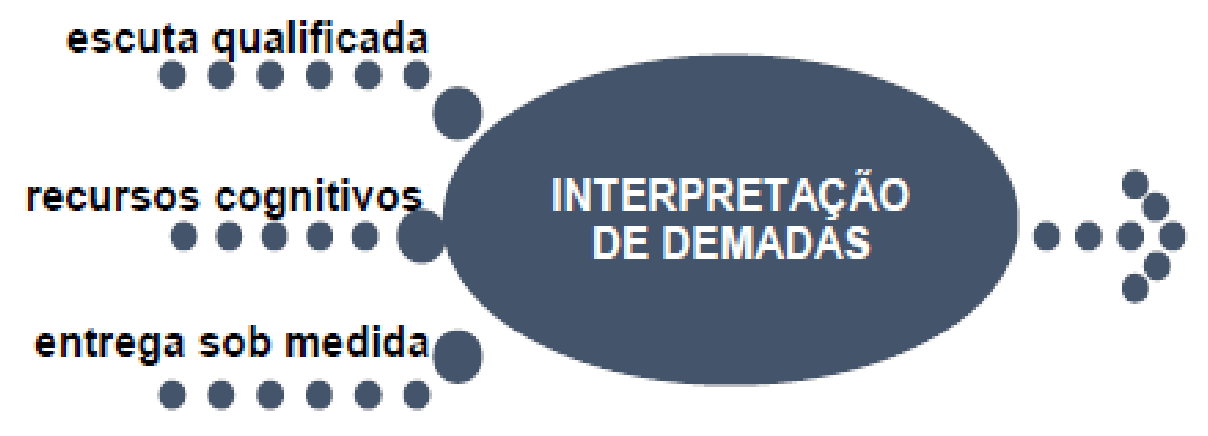

Esta competência foi relevante para a ENAP, quando, nos seus primeiros anos, compreendeu que deveria adotar a formação de outras carreiras, não somente aquela para a qual foi criada. Também foi importante no período de 1999 a 2001 quando se voltou para a formação de dirigentes e gerentes. Esta atuação era tão evidente em 2017, que a escola passou a ser reconhecida pela sua capacidade de interpretar as demandas do contexto institucional, configurando-se em uma competência distintiva. 
Discussão das competências desenvolvidas pela ENAP

Verificou-se que todas as competências organizacionais da ENAP são capacidades importantes e fonte de diferenciação para o desempenho dos seus papéis. Essas competências são geradas pelas habilidades e pelos conhecimentos coletivos, incorporadas aos diversos níveis organizacionais, explicitadas na sua atuação como escola de governo e percebidas e valorizadas pelos atores e pelas organizações públicas. $O$ esforço centrado na identificação das competências organizacionais a partir da narrativa dos participantes da pesquisa possibilitou compreender que o desenvolvimento de tais competências, ao longo da história organizacional da ENAP, apresenta uma relação estreita com: 1) o propósito da ENAP; as características únicas e peculiares que definem o diferencial da sua atuação; os possíveis aspectos valorizados pelos usuários quando acessam atividades e serviços ofertados e; as razões apontadas para a existência e continuidade da ENAP, como escola de governo. Em outras palavras, esse esforço de identificação das competências organizacionais considera que a formação e o desenvolvimento dessas competências estão imbricados na história organizacional da ENAP e no desempenho dos seus papéis.

Entende-se que a marca ENAP está relacionada ao seu propósito de criação. Além da legitimidade da marca para os participantes da pesquisa, hoje a escola é respeitada e reconhecida nacional e internacionalmente pelo desempenho do seu papel, enquanto escola de governo. Tal percepção é traduzi- da no momento em que são descritas as razões que justificam a sua existência. Razões para a continuidade e existência da ENAP, enquanto escola de governo, também estão associadas às suas competências e a ser espaço de encontro de competências. Há também aqueles que admitem que a ENAP não tem e nem deve ter uma característica única que a defina. Assim como há aqueles que afirmam que o diferencial da escola está apenas relacionado à infraestrutura física e à facilidade de contratação, no âmbito do setor público.

Um fator com grande potencial de influência no desenvolvimento das competências para as escolas de governo foi identificado nas narrativas: a política de gestão. No caso particular da história organizacional da ENAP: a ausência de uma política de gestão. É fundamental entender qual a contribuição que a capacitação pode dar. Para Pacheco (2000, 2002), é preciso ter uma política para a gestão pública: "Se esse assunto não for tratado como um campo de política pública, a capacitação fica sem rumo. É necessário ter uma proposta de para onde levar a organização e o funcionamento do Estado. Uma política para gestão pública que oriente a ENAP" (p.32).

A escola não pode só responder às demandas feitas. Tem que ser o radar e desenvolver uma competência de influenciar os dirigentes para a construção de uma política pública de gestão. Acho que faz parte da ideia de escola de governo (trecho de entrevista)

$\mathrm{Na}$ definição original empreendida por Barzelay (2001), citado por Martins (2003), "políticas de gestão pública referem-se a regras 
e rotinas que se aplicam à administração pública como um todo em relação à macro-organização governamental, processo de planejamento, orçamento e gestão financeira, funcionalismo, organização de sistemas e métodos, controle e avaliação e aquisições". (p. 22)

Para Martins (2003), adicionam-se a essa definição os processos de desenvolvimento institucional, voltados ao desenvolvimento das estratégias, alinhamento das estruturas, à otimização dos processos de trabaIho, adequação dos quadros funcionais e sistemas de informação, conhecimento e aprendizagem, não apenas na perspectiva macrogovernamental, mas também como parte da ação modernizadora de cada organização pública (Martins, 2003).

Desenvolver competências, para Nicolini \& Meznar (1995) citados por Bitencourt, Azevedo, \& Froehlich (2013) não é algo que a organização escolha fazer, mas é parte do que ela é. Segundos os autores, os processos que podem ser identificados como desenvolvimento de competências acontecem continuamente, quer sejam reconhecidos ou não como tais. Ou seja, a organização aprende a fazer aquilo que ela faz e que ela acredita fazer e, ao aprender, constrói a sua competência.

\section{CONCLUSÃO}

Esse estudo teve como objetivo compreender as competências organizacionais desenvolvidas pela ENAP como escola de governo, o que se cumpriu por meio de uma abordagem interpretativista e histórica. Ao construir a história da ENAP com foco nas competências desenvolvidas em função de sua atuação como escola de governo, no período de 1986 a 2016, evidenciaram-se: ter a marca ENAP; formar competência para a gestão; ser espaço de encontro de competências; e interpretar demandas.

Ter a marca ENAP é uma competência organizacional que se formou junto com a escola e seu objetivo inicial. Apesar dos momentos em que a marca ENAP apenas sobreviveu, hoje é reconhecida como diferencial na história e na atuação da escola. Os elementos que ajudam na constituição desta competência são: confiança, respeito e reconhecimento dos serviços prestados; qualidade na entrega de produtos e serviços; e flexibilidade e adaptação da entrega.

Formar competência para a gestão é uma competência organizacional. A sua expertise é a gestão, trazendo características únicas para a sua atuação e é a sua contribuição para uma das grandes fragilidades da gestão pública brasileira, marcada pela descontinuidade administrativa. Os elementos que sustentam esta competência são a conectividade com a ação e os problemas do governo, a diversidade do corpo docente e a prática do ensino aplicado.

Ser espaço de encontro de competências é uma competência organizacional que se constitui em capacidade distintiva da escola, que, apesar de não ter corpo docente próprio, tornou-se um ponto de encontro de pessoas, conhecimento e práticas competentes. Os elementos que constituem esta competência, ao longo do tempo, são: pessoas, produção e disseminação de conhecimento, cooperação e rede, e proposta pedagógica. Interpretar demandas é uma competência organizacional desenvolvida pela ENAP a 
partir do processo de "escuta" dos usuários da escola e da entrega dos serviços customizados de acordo com demandas específicas dos órgãos e gestores públicos. Os elementos que constituem essa capacidade são: escuta qualificada, recursos cognitivos e entrega sob medida.

A história dessas competências organizacionais foi marcada por processos adaptativos, emergentes e incrementais, principalmente quando se entende que as práticas são padrões reconhecidos, ainda que variem grandemente de acordo com o cenário em que são desempenhados, reconhecíveis e, pela sua própria execução, disseminam-se e modificam-se constantemente, recursivamente. A escola de governo deve mudar e construir-se ao longo do tempo. Em suspensão, fica a importância de um marco regulatório, diante da realidade processual e dinâmica das escolas de governo.

As competências organizacionais da ENAP apoiam mais que a oferta de seus serviços; têm relação direta com as suas estratégias deliberadas e emergentes, justificam a sua existência ao longo desses anos e sustentam a sua história. A ENAP esteve atenta, tanto aos seus recursos internos quanto aos externos, buscando como lidar com a complexidade do ambiente no qual está inserida. Tal comportamento organizacional propiciou, em certa medida, a formação e o desenvolvimento de habilidades de aquisição, aprendizagem e acumulação de ativos intangíveis, que neste estudo foram chamados de competências organizacionais. Por outro lado, o contexto político-institucional influenciou de maneira significativa a ação e as práticas da ENAP, bem como as decisões de alocação de capacidades e de re- cursos, em função do papel a ser desempenhado pela escola. A compreensão de que a história da ENAP está relacionada aos aspectos institucionais e cognitivos pode ser aprofundada em pesquisas futuras.

A história da ENAP não acabou, mas este estudo histórico de suas competências organizacionais é concluído nesse ponto, com sugestões para outras pesquisas: a história das escolas de governo, por meio dos acordos e das parcerias de cooperação internacional; a gestão das escolas de governo, à luz perspectiva da estratégia como prática social; a trajetória profissional dos egressos; a trajetória dos gestores versus a trajetória de escolas de governo. Essas duas últimas sugestões seriam também uma possível contribuição metodológica pela combinação de história oral temática e oral de vida.

\section{REFERÊNCIAS}

Amaral, H. K.do (2004). Escolas de Governo e Universidade: Parceria estratégica para aumentar a capacidade de governo. In: Conferência Brasil e União Européia Ampliada. Rio de Janeiro, RJ.

Amaral, H. K. do (2005). O papel da escola de governo na formação e capacitação dos quadros permanentes do Estado. Revista ResPvblica, 4(1), 85-105. Recuperado de:https://drive.google.com/file/ d/OBxnWe4FQdTbSTUxxU3J3cGM4Nm8/ edit

Barzelay, M.(2001) Research on Public Management Policy Change in Latin American Region: Conceptual Framework, Methodological Guide and Exemplars. IADB 
Becker, G. V. (2004). Trajetórias de Formação e desenvolvimento de competências organizacionais da Muri Linhas de Montagem. (PhD thesis). Postgraduate program of the Economics, Management and Accounting Faculty, São Paulo University, São Paulo.

Bitencourt, C., Azevedo, D., \& Froehlich, C. (2013) Na trilha das competências: Caminhos possíveis no cenário das organizações. Porto Alegre: Bookman.

Braun, V., \& Clark, V. (2006) Using thematic analysis in psychology. Qualitative Research in Psychology, 3(2), 77-101. doi:10.1191/1478088706qp063oa

Bryson, J. M., Ackermann, F., \& Eden, C. (2007). Putting the Resource-Based View of Strategy and Distinctive Competencies to Work in Public Organizations. Public Administration Review, 67(4). Recuperado de: http://citeseerx.ist.psu.edu/viewdoc /downlo ad?doi=10.1.1.475.6767\&rep=rep1\&type $=p$ df. doi: 10.1111/j1540621020000754x

Cellard, A. (2008). A análise documental. In: Poupart J., Deslauriers, J.-P., Groulx, L.-H., Laperriere, A., Mayer, R. , \& Pires, A. A pesquisa qualitativa: Enfoques epistemológicos e metodológicos (pp. 127-153) Rio de Janeiro: Vozes.

Clark, P., \& Rowlinson, M. (2004). The treatment of history in organization studies: towards an 'historic turn'? Business History, 46(3), 331- 352. doi: 10.1080 / 0007679042000219175

Cunliffe, A. (2011) Crafting Qualitative research: Morgan and Smircich 30 years on. Organizational Research Methods, (14), 647-

\section{3. doi:10.1177/1094428110373658}

Dias, J. (2011). O processo de formação, desenvolvimento e renovação de competências organizacionais em uma empresa brasileira de prestação de serviços de TI. (dissertação de mestradoPontifícia Universidade Católica do Rio Grande do Sul, Porto Alegre).

ENAP. (2004). Respeitando a história e construindo o futuro (Folder). Brasília, DF: Ministério do Planejamento. Recuperado de http:// repositorio.enap.gov.br/

ENAP. (2006). ENAP 20 anos: Caminhos de uma escola de governo. Cadernos ENAP (Edição Especial). Brasília: ENAP,104 p.

ENAP 30 Anos. (2016). Vídeo Institucional Escola de Administração Pública (Vídeo). Brasília, DF: Brasília Produtora. Recuperado de https://www.youtube.com/ watch? $v=1 \mathrm{fHCcMtE}$

198.

Ferrarezi, E., Zimbrão, A., \& Amorim, S. (2008). A Experiência da ENAP na Formação Inicial para a Carreira de Especialista em Políticas Públicas e Gestão Governamental - EPPGG: 1988 a 2006. Cadernos ENAP, 33.

Fernandes, C.C.C. (2015). Escolas de governo: Conceito, origens, tendências e perspectivas para sua institucionalização no Brasil. In: VIII Congresso CONSAD de Gestão Pública. Brasília, DF.

Fleury, M. T. L., \& Fleury, A. C. C . (2001). Construindo o conceito de competência. Revista Administração Contemporânea, 5 (special edition). doi: 10.1590/S141565552001000500010 . 
Fleury, M. T. L., \& Fleury, A. C. C . (2004). Alinhando estratégia e competências. Revista Administração de Empresas, 44(1),44-57. doi:10.1590/S0034-75902004000100012

Gaetani, F. (1994). Escolas de Governo: Limites e condicionalidades. Revista do Serviço Público, 2, p.116).

Gray, D. E. (2012). Pesquisa no mundo real. 2. ed. Porto Alegre: Penso.

Holanda, N. (2005). O contexto de criação da carreira de Especialista em Políticas Públicas e Gestão Governamental. Revista de Políticas e Gestão Governamental, 4(1), 17-38. Recuperado de https://drive.google. com/file/d/OBxnWe4FQdTbSZUpQcmJH VI9SWFU/edit

Kaehler, C. G. (2013). Framework de avaliação de competências organizacionais: $O$ caso de uma empresa brasileira de agenciamento marítimo. (dissertação de mestrado, Pontifícia Universidade Católica do Rio Grande do Sul, Porto Alegre)

Martins, H. F. (2003). Uma teoria da fragmentação de políticas: Desenvolvimento e aplicação na análise de três casos de políticas de gestão pública. (tese de PhD Fundação Getúlio Vargas, Rio de Janeiro).

Meihy, J. C. S., \& Ribeiro, S. L.S. (2011). Guia Prático de história oral. São Paulo: Contexto.

Munck, L., \& Dias, B. G. (2013). Avanços e Desafios da Conceituação e Operacionali- zação das Competências Organizacionais. In: Anais Eletrônicos do XXXVII Encontro da Associação Nacional Dos Programas de Pós-graduação em Administração. Rio de Janeiro, RJ.

Pacheco, R. S. (2000). Escolas de Governo: Tendências e desafios - ENAP Brasil em perspectiva comparada. Revista do Serviço Público, 51(2), 35-53. doi:10.21874/rsp. v51i2.324

Pacheco, R. S (2002) Escolas de governo como centros de excelência em gestão pública: A perspectiva da ENAP-Brasil. Revista do Serviço Público, 53(1), 75-88. doi:10.21874/rsp.v53i1.280

Quintana, R. (2009) O processo de formação e desenvolvimento de competências organizacionais em uma instituição do setor público. (2009).(dissertação de mestrado, Pontifícia Universidade Católica do Rio Grande do Sul.)

Ruas, R., Ghedine, T., Dutra, J. S., Becker, G. V., \& Dias, G. B. (2005). O conceito de competência de $A$ à $Z$ - análise e revisão nas principais publicações nacionais entre 2000 e 2004. Anais do Encontro Nacional da Associação Nacional de Pós-Graduação e Pesquisa em Administração, Brasília, DF.

Silva, M. R. (2017). História organizacional da ENAP: Uma análise dos papéis desempenhados e das competências desenvolvidas. (tese de doutorado, Universidade Federal da Bahia, Escola de Administração, Salvador). 